\title{
PROTECTING POLLINATED BLOSSOMS
}

\author{
Dr. William S. Chafin, Vanderbilt, Mich.
}

I $\mathrm{N}$ cross-pollinating flowers, it is often necessary for the plant breeder to visit a blossom twice: the first time to remove the pollen from the flower, so it will have no opportunity to pollinate itself, and a second time when the stigmas are in a receptive condition, to apply the pollen from some other plant which he has selected as the male parent of the hybrid.

Between these two visits, it is of the utmost importance that foreign pollen, which might be carried by the wind or insects, be excluded-otherwise the results of the experiment will be thrown into confusion. It is also necessary, in most cases, to protect the pollinated flower for some time after the cross has been effected, for the same reason. Both these objects are usually accomplished by enclosing the flower in a cloth or paper sac, which of course must be removed when the flower is pollinated.

Removing these sacs and replacing them without injuring delicate flowers is sometimes a little difficult. A device which I have found very convenient because of the ease with which it may be opened or closed for this purpose and held in the fingers without danger of injuring the flower is seen in Fig. 9.

A strip of fine muslin of the proper width (a tag end of which is shown at A) is folded lengthwise, stitched along

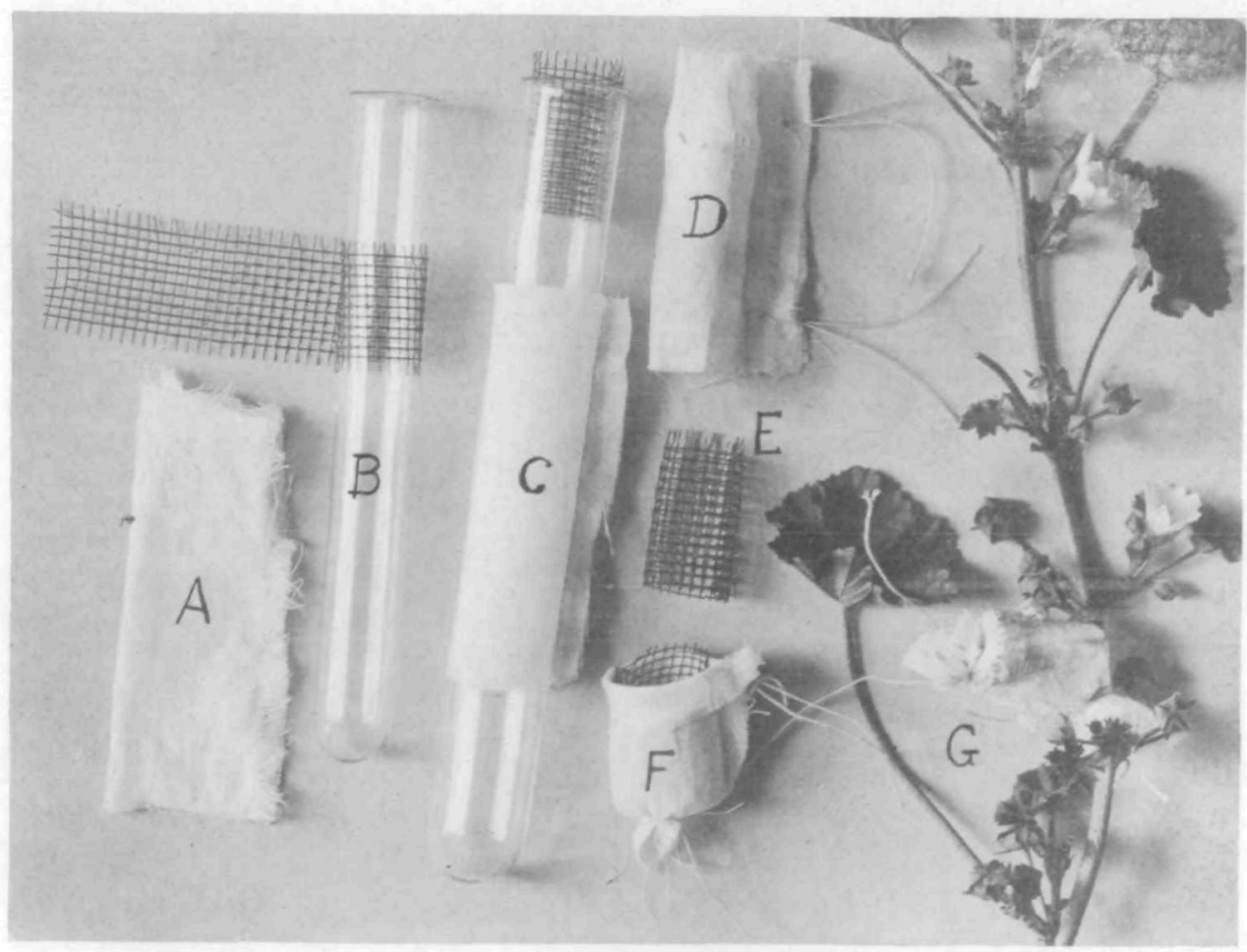

\section{CONVENIENT BAG FOR PROTECTING POLLINATED FLOWERS}

It is distended by a frame of wire netting, which allows it to be put on or taken off the flower with little danger of injury to even the most delicate blossom. The use of a test-tube, as described in the text and shown at $E$ above, allows the cloth to be slipped over the screen without any trouble from catching ends of the wire. (Fig. 9.) 
the edges and cut into pieces long enough to fasten easily over the ends of a wire frame (E). This is formed, as seen at (B), by bending a strip of wire netting around a test tube and turning back the ends of the long wires to hold the frame together. The frame is now cut off and inserted in the muslin tube by means of a somewhat larger test tube (C). A piece of fine copper wire at each end completes the whole. (D).

To use, one end of the cloth is turned back over the frame like a cuff (F). It is then slipped over the flower and the cloth fastened about the stem with a few twists of wire as at (G). The frame may then be readily opened to inspect or pollinate the flower by simply untwisting the upper wire and turning back the cloth.

Light cardboard may be substituted for the wire netting, but is not as good in case of rain. The size of the frame should be varied, of course, to suit the case. Where the flowers are small and gathered at the end of a stem it is better to use a large sac and enclose the whole cluster.

No positive claim is made for originality as the device is one which might occur to anybody and doubtless has been used by others.

\section{Plant Breeding in Minnesota}

More than 300,000 plants a year are handled by the breeders of the Minnesota Agricultural Experiment Station, mostly with the object of increasing yield or hardiness. In alfalfa, the object is to produce better seed-bearing strains. Sugar beets are crossed with mangels to produce a good stock beet. Commercial varieties of grape have been carefully studied, some being found to be self-sterile and some self-fertile. In the self-sterile forms, the generative nucleus becomes degenerated, which prevents the further functioning of the pollen grain. This is believed to be the first time that the actual cause of self-sterility in grapes has been determined; obviously no cultural expedients can possibly overcome such a trouble, and the only remedy is the use of proper varieties. It will be recalled that the native American grapes, as a class, seem to be practically monoecious in nature. Although bearing vines produce male as well as female flowers, their female flowers are usually incapable of pollination from male flowers on the same vine, and depend on cross-pollination from vines that bear exclusively male flowers and-of course-no fruit. Such is the condition among the wild vines; but in the commercial varieties which have been created from them this habit has been modified, until in many cases a bearing vine produces good pollen for its own female flowers, and the planting of distinct male vines is unnecessary. Evidently, however, this habit is not well enough fixed to be wholly dependable, and is better fixed in some varieties than others. The scientific grape grower, then, will ascertain before planting just how the varieties he has picked out will behave when self-pollinated, and if they do not take kindly to this artificial means of fecundation, he will plant out enough male vines to insure a crop. Similar work has been done with the plum and strawberry. Statistical studies of the characters of many fruits are being made.

\section{Why Do Apples Bloom Late?}

The main breeding problem at the Virginia Agricultural Experiment Station is with apples, and the investigators are making a determined effort to find whether the late blooming attribute is a hereditary quality transmitted by definite discoverable laws. In addition there are genetic studies of color inheritance in lupins, phlox and other ornamentals, and a study of the possible inheritance of disease in the tomato. 